\title{
Mice Deficient in the Polysialyltransferase ST8SialV/PST-1 Allow Discrimination of the Roles of Neural Cell Adhesion Molecule Protein and Polysialic Acid in Neural Development and Synaptic Plasticity
}

\author{
Matthias Eckhardt,, ${ }^{1}$ Olena Bukalo, ${ }^{3}$ Geneviève Chazal, ${ }^{2}$ Lihua Wang, ${ }^{1}$ Christo Goridis, ${ }^{2}$ Melitta Schachner, ${ }^{3}$ \\ Rita Gerardy-Schahn, ${ }^{1}$ Harold Cremer, ${ }^{2}$ and Alexander Dityatev ${ }^{3}$
}

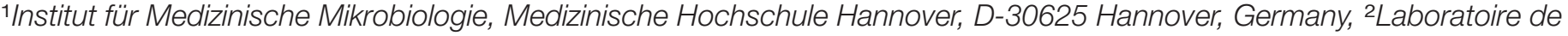
Génétique et Physiologie du Développement, IBDM, Centre National de la Recherche Scientifique, Institut National de la Santé et de la Recherche Médicale, Université de la Méditerranée, F-13288 Marseille, France, and '3Zentrum für Molekulare Neurobiologie, Universität Hamburg, D-20246 Hamburg, Germany

Functional properties of the neural cell adhesion molecule (NCAM) are strongly influenced by polysialylation. We used genetargeting to generate mice lacking ST8SialV/PST-1, one of the polysialyltransferases responsible for addition of polysialic acid (PSA) to NCAM. Mice homozygous for the null mutation reveal normal development of gross anatomical features. In contrast to NCAM-deficient mice, olfactory precursor cells in the rostral migratory stream express PSA and follow their normal pathway. Furthermore, delamination of mossy fibers in the hippocampal CA3 region, as found in NCAM-deficient mice, does not occur in ST8SialV mutants. However, during postnatal development these animals show a decrease of PSA in most brain regions compared to wild-type animals. Loss of PSA in the presence of NCAM protein but in the absence of obvious histological changes allowed us to directly address the role of PSA in synaptic plasticity. Schaffer collateral-CA1 synapses, which express PSA in wild types, showed impaired long-term potentiation (LTP) and longterm depression (LTD) in adult mutants. This impairment was age-dependent, following the time course of developmental disappearance of PSA. Contrary to NCAM mutant mice, LTP in ST8SialV mutants was undisturbed at mossy fiber-CA3 synapses, which do not express PSA in wild-type mice. The results demonstrate an essential role for ST8SialV in synaptic plasticity in hippocampal CA1 synapses, whereas PSA produced by different polysialyltransferase or polysialyltransferases at early stages of differentiation regulates migration of neural precursor cells and correct lamination of mossy fibers. We suggest that NCAM but not PSA is likely to be important for LTP in the hippocampal CA3 region.

Key words: gene targeting; hippocampus; long-term potentiation; long-term depression; neural cell adhesion molecule; polysialic acid; polysialyltransferase
The neural cell adhesion molecule (NCAM) is a major regulator of cell-cell and cell-substratum interactions involved in neurite growth, cell migration, and synaptic plasticity (Mayford et al., 1992; Goodman et al., 1997; Schachner, 1997). In vertebrates, polysialic acid (PSA) is the most striking post-translational modification of NCAM, known to modulate functional properties of NCAM (for review, see Rutishauser, 1996; Kiss and Rougon, 1997; Mühlenhoff et al., 1998). Whereas in early development (in mice up to embryonic days 8 and 9) NCAM does not carry PSA, the polysialylated NCAM-isoforms (PSA-NCAM) become predominant at later stages and reach a maximum in the perinatal phase. However, after birth the amount of PSA progressively declines, and only a minor fraction of NCAM remains in its polysialylated state (for review, see Seki and Arai, 1993; Rutishauser and Landmesser, 1996). In

\footnotetext{
Received Nov. 10, 1999; revised March 31, 2000; accepted April 26, 2000.

This work was supported by grants from European Community BIO 4 CT 960730 M.E. was supported by a postdoctoral fellowship from the Deutsche Forschungsgemeinschaft. We greatly appreciate suggestions of T. Katafuchi and P. Castillo regarding mossy fiber-CA3 LTP recordings, G. Rougon for support and discussion, W. Anderson for sharing the LTP101M program, M. Leitges for the neo/LacZ cassette and R. Kühn for E14-1 ES cells. B. Gotza and A. Bethe are acknowledged for expert technical assistance.

Correspondence should be addressed to Dr. Harold Cremer, Laboratoire de Génétique et Physiologie du Développement, IBDM, Centre National de la Recherche Scientifique, Institut National de la Santé et de la Recherche Médicale, Université de la Méditerranée, Campus de Luminy, Case 907, F-13288 Marseille Cedex 9, France. E-mail: cremer@ibdm.univ-mrs.fr or Dr. Rita Gerardy-Schahn, Institut für Medizinische Mikrobiologie, Medizinische Hochschule Hannover, Carl-Neuberg-Strasse 1,

D-30625 Hannover, Germany. E-mail: Rita.Gerardy-Schahn@gmx.de.

Dr. Eckhardt's present address is Institut für Physiologische Chemie, Universität Bonn, Nussallee 11, D-53115 Bonn, Germany.

Copyright (C) 2000 Society for Neuroscience $0270-6474 / 00 / 205234-11 \$ 15.00 / 0$
}

the adult brain, PSA-NCAM remains expressed in neuronal populations showing ongoing neurogenesis, cell migration, axonal outgrowth, and synaptic plasticity. Examples are the rostral migratory stream (Lois et al., 1996), the hippocampal formation (Seki and Arai, 1993), and the hypothalamic nuclei (Theodosis et al., 1991; Glass et al., 1994).

Two related enzymes are responsible for sialic acid polymerization in vertebrates, ST8SiaII (STX; Livingston and Paulson, 1993; Yoshida et al., 1995) and ST8SiaIV (PST or PST-1; Eckhardt et al., 1995; Nakayama et al., 1995; Mühlenhoff et al., 1996a; Nakayama and Fukuda, 1996), both differing markedly with respect to their spatial and temporal expression patterns (Kurosawa et al., 1997; Phillips et al., 1997; Wood et al., 1997; Hildebrandt et al., 1998; Ong et al., 1998). ST8SiaII is the predominant form in the embryo, whereas ST8SiaIV persists at relatively high levels in the postnatal brain (Hildebrandt et al., 1998; Ong et al., 1998).

Several recent observations provide strong evidence that PSA is required for some forms of synaptic plasticity in the mammalian brain (Becker et al., 1996; Muller et al., 1996). Furthermore, long-term potentiation (LTP) is strongly affected in the Schaffer collateral-CA1 and mossy fiber-CA3 synapses in NCAM- deficient mice (Muller et al., 1996; Cremer et al., 1998). However, because both PSA and NCAM are absent from these mice throughout development and in the adult, it is difficult to distinguish between PSA- and NCAM-dependent phenomena on one hand and between developmental and acute functions on the other.

Disrupting the genes for the polysialyltransferases leaves the NCAM protein intact, thus allowing the distinction between NCAM and PSA deficiency. Furthermore, because both enzymes are differentially expressed, it is possible to create mice lacking 
a

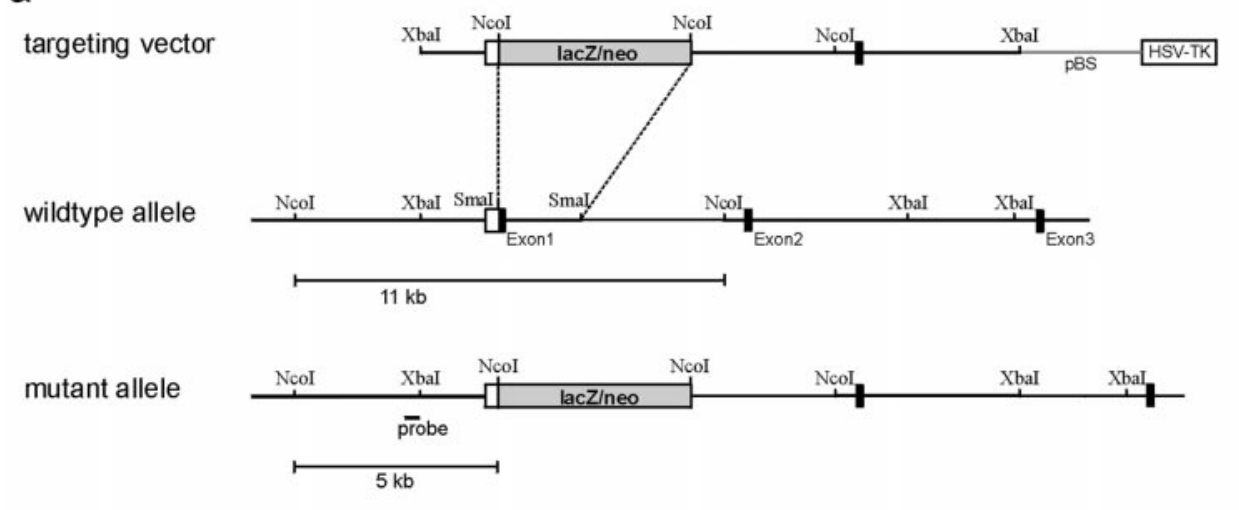

b

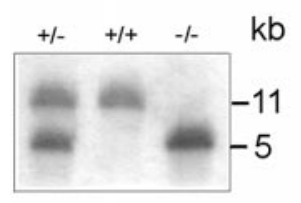

P21

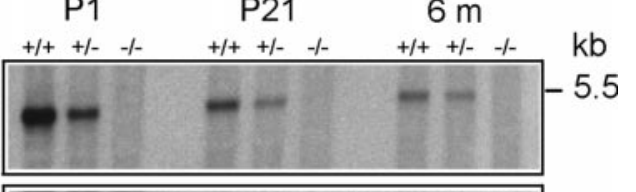

C

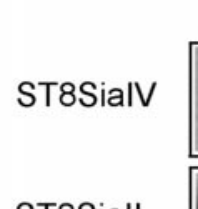

ST8Siall



NCAM

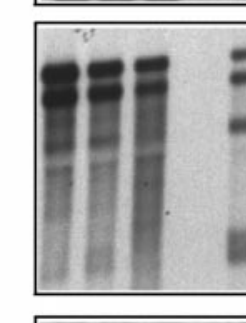

Figure 1. Targeted disruption of the ST8SiaIV gene. $a$, Targeting construct, wild-type ST8SiaIVgene, and the mutant allele resulting from homologous recombination. Restriction sites for NcoI, SmaI, and $X b a \mathrm{I}$ are indicated. A black bar indicates the location of fragments used to generate the 5'-RNA probe. $b$, Southern blot analysis of ES cells and mouse tailDNA form the $F_{2}$ generation showing wild-type $(+/+)$, heterozygous $(+/-)$, and homozygous mutants $(-/-)$. Genomic DNA was digested with NcoI and hybridized to the $5^{\prime}$-probe indicated in $a$. c, Northern blot analysis of poly(A) ${ }^{+}$ RNA from wild-type $(+/+)$, heterozygous $(+/-)$, and homozygous $(-/-) \mathrm{F}_{2}$ mice. RNA was isolated from total brain of 1-day-old (P1), 21-d-old (P21), and 6-month-old $(6 \mathrm{~m})$ animals. No ST8SiaIV signal could be detected in homozygous mutants, whereas a specific signal is detectable in wild-type and heterozygous mice. In the latter, the signal intensity is reduced by $\sim 50 \%$. Probing the blots with ST8SiaII and NCAM-specific probes revealed no differences in the expression level.

PSA only in a subset of tissues or cell types and certain periods of development. We used gene targeting to create mice lacking a functional ST8SiaIV/PST-1-gene. These mice exhibit normal development and morphological features, including migration of neural precursors and fasciculation of mossy fibers, but show a specific loss of PSA in mossy fibers of the CA3-CA4 and the CA1 region. This loss was accompanied by impairment of synaptic plasticity at Schaffer collateral-CA1 synapses in adult, but not in young mice. In contrast, LTP appeared unaffected at mossy fiber-CA3 synapses, demonstrating a specific and essential role for PSA in synaptic plasticity at the Schaffer collateral-CA1 pyramidal cell synapse.

\section{MATERIALS AND METHODS}

Generation of a targeted mutation in the ST8SiaIV gene. A genomic clone $\lambda 11.1$ harboring the promoter and the first three exons of murine ST8SiaIV was isolated from a murine 129/Sv $\lambda$ phage library (Eckhardt and Gerardy-

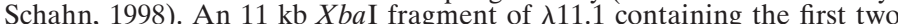
exons was subcloned into pBluescript SK $(-)$. The resulting clone pl11 was digested with SmaI and EcoRV, which released two small fragments containing the coding region of exon 1 and the $5^{\prime}$-region of intron 1 and a $8 \mathrm{~kb}$ fragment containing part of introns 1 and 2 and exon 2. The latter fragment was religated to the vector that contained the $1.5 \mathrm{~kb}$ of the $5^{\prime}$-end of the genomic fragment. Thus, in the resulting plasmid pME16, $\sim 2 \mathrm{~kb}$ are removed from the gene by eliminating the coding region of exon 1 , including 8 nucleotides upstream of the ATG start codon and $1.4 \mathrm{~kb}$ of intron 1. The lacZ/neo cassette was isolated from the vector pLR lacZpA/ MCINeopA (a gift from M. Leitges MPI for Immunobiology, Freiburg, Germany) by digesting with NcoI. The fragment was rendered blunt by using Klenow enzyme and introduced into the SmaI-digested plasmid pME16. The thymidine kinase gene of plasmid pIC19R/MCI-TK (Mansour et al., 1988) was cloned into the SalI site of pME16. The targeting vector (Fig. 1a) was linearized with SmaI and electroporated into E14-1 embryonic stem (ES) cells (gift from R. Kühn, Institut für Genetik Universität, Köln, Germany) by electroporation ( $25 \mu \mathrm{g}$ of DNA per $10^{7}$ cells $)$ using a Bio-Rad (Munich, Germany) gene pulser (240 V, $500 \mu \mathrm{F})$. Cells were grown on mitomycin C (Sigma-Aldrich, Deisenhofen, Germany)treated embryonic fibroblasts, and positive-negative selection was performed using $350 \mu \mathrm{g} / \mathrm{ml}$ G418 (Life Technologies, Cergy Pontoise, France) and $2 \mu \mathrm{M}$ gancyclovir (Cymevan Roche). Surviving colonies were picked after $12 \mathrm{~d}$ and transferred into 96 well plates in duplicate. Genomic DNA was isolated, digested with $\mathrm{NcoI}$, and analyzed for homologous recombination by Southern blotting with a 5 '-probe that hybridizes to the ST8SiaIV promoter region immediately upstream of the short arm of the targeting vector (Eckhardt and Gerardy-Schahn, 1998). Of 770 clones tested, a single clone revealed homologous recombination. For unknown reasons, $\beta$-galactosidase activity could not be detected in adult knock-out mice. Male chimeras were bred to $\mathrm{C} 57 \mathrm{BL} / 6 \mathrm{~J}$ females, and resulting heterozygous F1 mice for the ST8SiaIV gene were crossed to produce homozygous mutants. Genotyping was performed by Southern blot analysis using the external $5^{\prime}$-probe.

Northern blot analysis. Brains were removed and immediately frozen in liquid nitrogen. Samples were homogenized in $4 \mathrm{M}$ guanidinium isothiocyanate, $50 \mathrm{~mm}$ sodium acetate, $\mathrm{pH}$ 5.2, and RNA was isolated from lysates by $\mathrm{CsCl}$ gradient centrifugation (Sambrook et al., 1989). Poly(A) ${ }^{+}$RNA was enriched using Oligotex (Qiagen, Hilden, Germany). Five micrograms of poly(A) ${ }^{+}$RNA was electrophoresed in a $1 \%$ agarose $/ 1 \mathrm{M}$ formaldehyde gel in $20 \mathrm{~mm}$ 4-morpholinepropanesulfonic acid, $\mathrm{pH}$ 7.0, $10 \mathrm{~mm}$ sodium acetate, and $1 \mathrm{~mm}$ EDTA and transferred to a nylon membrane (Qiagen). Nylon filters were hybridized overnight at $65^{\circ} \mathrm{C}$ in high-SDS buffer $(5 \times$ SSC, $50 \%$ formamide, $50 \mathrm{~mm}$ sodium phosphate, $7 \%$ SDS, and $1 \%$ blocking reagent; Boehringer Mannheim, Mannheim, Germany) to digoxigeninlabeled antisense RNA probes transcribed from the coding regions of mouse ST8SiaIV (Eckhardt and Gerardy-Schahn, 1998), mouse ST8SiaII (Kojima et al., 1996), and mouse NCAM (Hildebrandt et al., 1998), respectively. After hybridization, the filters were washed twice in $2 \times$ SSC, $0.1 \%$ SDS at room temperature for $5 \mathrm{~min}$ and twice in $0.1 \times \mathrm{SSC}, 0.1 \%$ SDS at $65^{\circ} \mathrm{C}$ for $20 \mathrm{~min}$. Bound probes were detected by incubation with anti-digoxigenin Ig-alkaline phosphate-conjugate (Boehringer Mannheim), which was revealed by chemiluminescence using disodium-3-(4methoxyspiro $\left\{1,2\right.$-dioxetane-3, $2^{\prime}$-(5' -chloro)tricyclo-[3.3.1.1 $\left.{ }^{3,7}\right]$ decan $\}-4$ yl)phenylphosphate (Boehringer Mannheim) as a substrate.

Western blot analysis. Tissue samples from different organs or brain regions were homogenized in $20 \mathrm{~mm}$ Tris- $\mathrm{HCl}, \mathrm{pH} 8.0,150 \mathrm{~mm} \mathrm{NaCl}, 5$ $\mathrm{mM}$ EDTA, $1 \mathrm{~mm}$ PMSF, and $200 \mathrm{U} / \mathrm{ml}$ aprotinin and lysed by adding $2 \%$ 


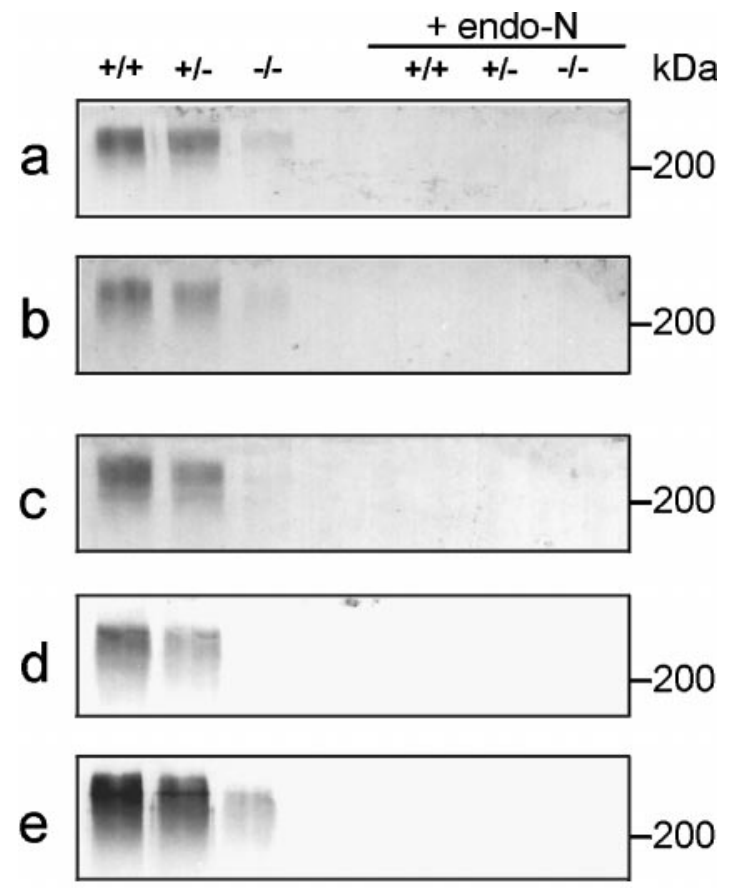

Figure 2. PSA expression in different brain regions of 5- to 6-week-old mice. Western blots of total lysates $(50 \mu \mathrm{g} /$ lane $)$ of olfactory bulb $(a)$, medulla oblongata $(b)$, hippocampus $(c)$, neocortex $(d)$, and hypothalamus (e) from wild-type $(+/+)$, heterozygous $(+/-)$, and mutant $(-/-)$ mice were probed with PSA monoclonal antibody 735 . Lack of immunoreactivity after endo-N treatment demonstrates the specificity of the immunostaining.

Triton X-100. Lysates were centrifuged for $30 \mathrm{~min}$ at $15,000 \times \mathrm{g}$, and the supernatant was mixed with an equal volume of $120 \mathrm{~mm}$ Tris-HCl, $\mathrm{pH}$ 6.8, $4 \%$ SDS, $20 \%$ glycerol, $5 \% \beta$-mercaptoethanol, and $0.01 \%$ bromophenol blue. Samples were subjected to SDS-PAGE and Western blot analysis (Mühlenhoff et al., 1996b). Membranes were incubated with anti-PSA mAb $735(10 \mu \mathrm{g} / \mathrm{ml})$ (Frosch et al., 1985) or anti-NCAM mAb KD11 (ascites fluid diluted 1:1000) (Gerardy-Schahn and Eckhardt, 1994), respectively, in $2 \%$ nonfat dry milk in PBS. Primary antibodies were detected with anti-mouse Ig-alkaline phosphate conjugate (Dianova, Hamburg, Germany) using nitroblue tetrazolium and 5-bromo-4-chloro-3-indolyl phosphate in $100 \mathrm{~mm}$ Tris- $\mathrm{HCl}, 100 \mathrm{~mm} \mathrm{NaCl}, 5 \mathrm{~mm} \mathrm{MgCl}_{2}, \mathrm{pH} 9.5$, as substrate. To remove PSA, samples were treated with endoneuraminidase-N (endo-N) before subjecting them to SDS-PAGE (Mühlenhoff et al., 1996b).

Immunohistochemistry and histology. Animals were perfused with $4 \%$ paraformaldehyde in PBS. Brains were removed and post-fixed overnigh in the same solution. Immunohistochemical staining was performed on 30 and $50 \mu \mathrm{m}$ Vibratome sections in DMEM/10\% fetal calf serum using monoclonal antibody 735 against PSA (Frosch et al., 1985), and rabbit antiserum against mouse NCAM (Gennarini et al., 1986), followed by Cy3(Dianova) or fluorescein isothiocyanate- and tetramethylrhodamine isothiocyanate-conjugated secondary antibodies (Sigma). Timm's staining was performed as described (Cremer et al., 1997).

Schaffer collateral-CA1 recordings. Thirteen- to 19-d-old, 4- to 5-weekold, and 4- to 6-month-old ST8SiaIV ${ }^{-1-}$ mice with mixed $\mathrm{C} 57 \mathrm{BL} / 6 \mathrm{~J}$ and $129 /$ Ola genetic background (C57BL/6J $\times 129 / \mathrm{Ola})$ and age-matched groups of wild-type C57BL/6J, 129/Ola, or C57BL/6J $\times 129 /$ Ola mice were used in electrophysiological experiments. After halothane anesthesia, decapitation and removal of the brain, the hippocampi were cut with a Vibroslice (Campden Instruments) in ice-cold artificial CSF (ACSF) containing (in mM): 250 sucrose, $25 \mathrm{NaHCO}_{3}, 25$ glucose, $2.5 \mathrm{KCl}, 1.25$ $\mathrm{NaH}_{2} \mathrm{PO}_{4}, 2 \mathrm{CaCl}_{2}$, and $1.5 \mathrm{MgCl}_{2}, \mathrm{pH}$ 7.3. The slices (400- $\mu \mathrm{m}$-thick) were kept at room temperature in a large chamber $(500 \mathrm{ml})$ filled with carbogenbubbled ACSF, containing $125 \mathrm{~mm} \mathrm{NaCl}$ instead of $250 \mathrm{~mm}$ sucrose, at least $2 \mathrm{hr}$ before the start of recordings (modified from Edwards et al., 1990). In the recording chamber, slices were continuously superfused with carbogen-bubbled ACSF (2-3 ml/min). Focal field EPSP (fEPSP) recordings were performed in the stratum radiatum with glass pipettes filled with ACSF and having a resistance of $2 \mathrm{M} \Omega$. Schaffer collaterals were stimulated concomitantly by two bipolar electrodes placed from both sides of the recording electrode in the stratum radiatum of the CA1 region. One of the electrodes was used to induce LTP by theta-burst stimulation (TBS) applied orthodromically. The second electrode was used for antidromic stimulation of the independent control pathway. Basal synaptic transmission was monitored at $0.05 \mathrm{~Hz}$. The inter-TBS interval was $20 \mathrm{sec}$, and five TBSs were applied to induce LTP. TBS consisted of 10 bursts delivered at $5 \mathrm{~Hz}$ (Muller et al., 1996). Each burst consisted of four pulses delivered at $100 \mathrm{~Hz}$. Duration of pulses was $0.2 \mathrm{msec}$, and stimulation strength was in the range of $30-60 \mu \mathrm{A}$ to provide fEPSPs with an amplitude of $50 \%$ from the subthreshold maximum. Homosynaptic long-term depression (LTD) was induced by two trains applied at $1 \mathrm{~Hz}$ for $10 \mathrm{~min}$ with a $10 \mathrm{~min}$ interval between them (Kerr and Abraham, 1995). Stimulation strength during baseline recordings and after induction of LTD was set to be $30-40 \%$ of maximal fEPSPs. It was $60-70 \%$ when $1 \mathrm{~Hz}$ trains were delivered. Field EPSPs were amplified and filtered at $1 \mathrm{kHz}$ using CyberAmp 320. Data acquisition and analysis were performed using the LTP101M program (Anderson and Collingridge, 1997).

Mossy fiber-CA3 recordings. The slices were prepared similarly as for recordings in the CA1 region, with some modifications. Before decapitation, mice were transcardially perf used with ice-cold ACSF, containing (in mM): 250 sucrose, $25 \mathrm{NaHCO}_{3}, 25$ glucose, $2.5 \mathrm{KCl}, 1.25 \mathrm{NaH}_{2} \mathrm{PO}_{4}, 0.5$ $\mathrm{CaCl}_{2}$, and $6 \mathrm{MgCl}_{2}, \mathrm{pH} \mathrm{7.3.} \mathrm{Slices} \mathrm{were} \mathrm{cut} \mathrm{according} \mathrm{to} \mathrm{Claiborne} \mathrm{and}$ colleagues (1993). Exchange of sucrose-containing ACSF to normal ACSF (with $2.5 \mathrm{mM} \mathrm{CaCl}_{2}$ and $1.5 \mathrm{mM} \mathrm{MgCl}_{2}$ ) was performed gradually using peristaltic pumps. In one set of experiments, the slices were kept in a large chamber before recording, as for the CA1 recordings. In another set of experiments, the slices were incubated for $3 \mathrm{hr}$ at room temperature in a small chamber with a volume of $3 \mathrm{ml}$ in ACSF containing or not containing endo-N. Treatment with endo-N resulted in a complete loss of PSA immunostaining in slices from mutant and wild-type mice. The stimulating electrode was placed close to the internal side of the granule cell layer. The recording electrode was placed in the stratum lucidum. Both, recordings and stimulations were performed with glass pipettes filled with ACSF and having a resistance of $2 \mathrm{M} \Omega$. The LTP-inducing high-frequency stimulation (HFS) consisted of trains of stimuli applied at $100 \mathrm{~Hz}$ during $1 \mathrm{sec}$ and repeated four times with an interval of $20 \mathrm{sec}$. To evoke LTP exclusively in mossy fiber synapses, which are known to undergo LTP in a NMDA receptor-independent manner, the NMDA receptor antagonist (AP-5; 50 $\mu \mathrm{M}$; Tocris Cookson, Bristol, UK) was applied $15 \mathrm{~min}$ before and during HFS. To confirm that the field EPSPs recorded were evoked by the stimulation of mossy fibers and not by the associational/commissural pathway, an agonist of metabotropic glutamate receptors (L-CCG1, $10 \mu \mathrm{M}$; Tocris) was applied at the end of each experiment (Cremer et al., 1998). Effects produced by stimulation or pharmacological treatments are given as mean \pm SEM percentage of the baseline value. Differences between groups were tested for significance using one-way ANOVA.

\section{RESULTS}

\section{Generation of ST8SialV ${ }^{-/-}$mice}

The murine ST8SiaIV gene was inactivated by replacing the first exon, which encodes the small cytosolic amino terminus and the transmembrane region by a lacZ/neo cassette (Fig. 1a). The targeting vector was transfected into E14-1 ES cells, and cells in which homologous recombination had occurred were identified by Southern blot analysis of genomic DNA. One homologous recombinant was found out of $770 \mathrm{ES}$ cell clones tested that had survived G418/gancyclovir positive-negative selection. This clone was then used to create $129 /$ Ola-C57BL/6J chimeric mice and eventually animals homozygous for the null mutation (Fig. 1b). Mice from heterozygous parents were born at the expected Mendelian proportions. No significant differences in body weight or brain size between mutant and wild-type mice up to 6 weeks of age were observed. In particular, the size of the olfactory bulb was not reduced in ST8SiaIV ${ }^{-1-}$ mice, in contrast to what has been found in NCAM-deficient mice (Tomasiewicz et al., 1993; Cremer et al., 1994). Histochemical examination of the brain revealed no obvious abnormalities (data not shown).

Absence of ST8SiaIV expression in ST8SiaIV ${ }^{-1-}$ mice was verified by Northern blot analysis (Fig. 1c). Hybridization of mRNA from brains of 1-d-old, 21-d-old, and 6-month-old mice to a ST8SiaIV-specific RNA probe gave no signals for homozygous mutants, whereas in heterozygous mice the signal intensities were reduced by $\sim 50 \%$, as expected. Probing the blots with a ST8SiaII RNA probe revealed that the expression level of this polysialyltransferase remained unchanged. Thus, there appears to be no detectable compensatory upregulation of ST8SiaII or replacement of ST8SiaIV expressing cells by ST8SiaII expressing cells in the mutant animals. Furthermore, expression of NCAM mRNA was identical between genotypes in sizes of the three major NCAM isoforms and at the quantitative level.

\section{PSA expression in ST8Sialv ${ }^{-/-}$mice}

Because only one of the two presently identified enzymes capable of synthesizing PSA is affected in ST8SiaIV ${ }^{-1-}$ mice, we used Western blot analysis to examine mutant mice for changes in PSA 

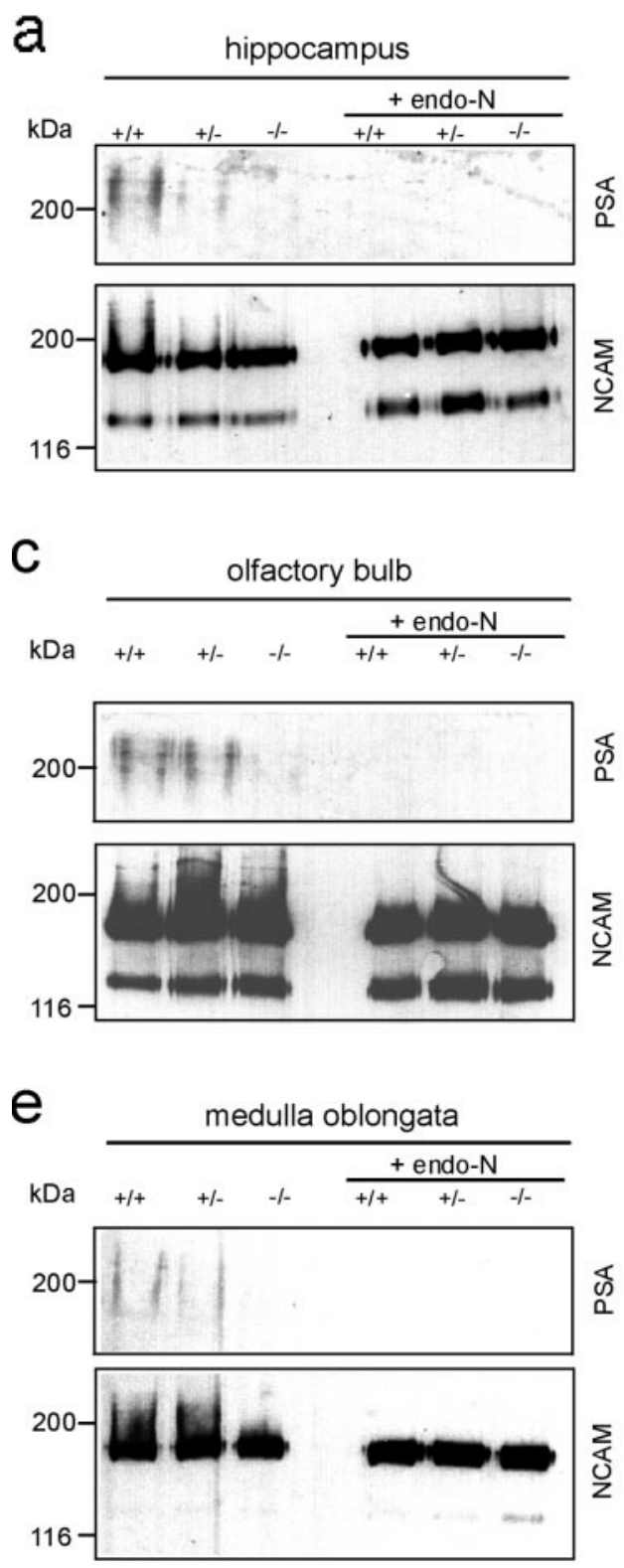
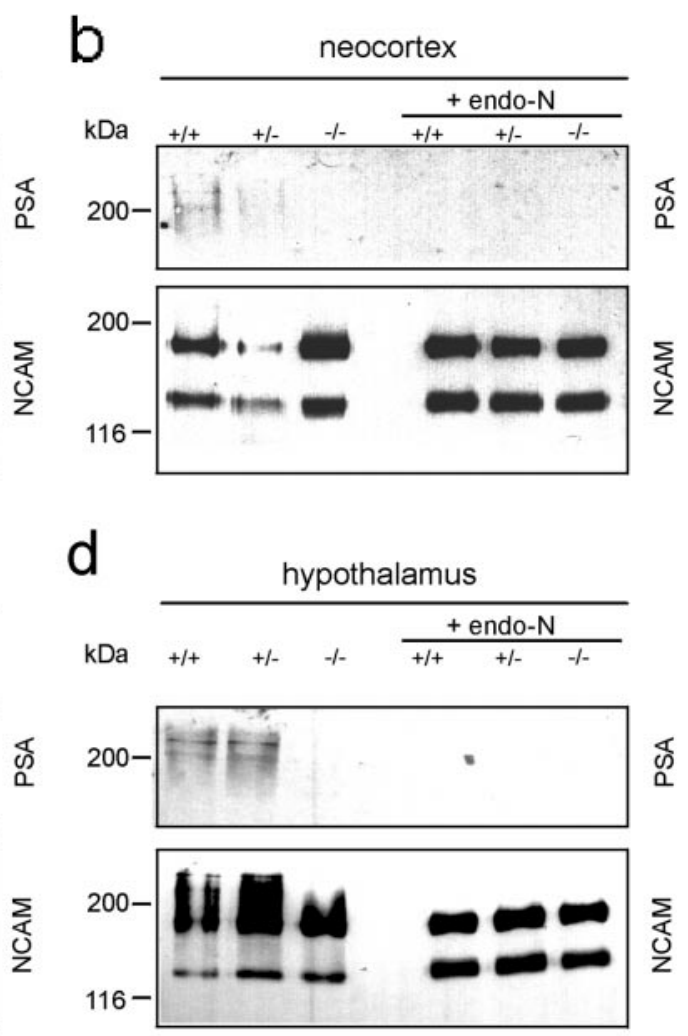

expression. Different organs (kidney, heart, spleen, and thymus) known to transiently express PSA during postnatal development (Lackie et al., 1993) were investigated $4 \mathrm{~d}$ and 5 weeks after birth. No significant differences in PSA expression between the different genotypes were observed in any of the tissues tested at either age (data not shown). Furthermore, at postnatal day four, the total amount of PSA expressed in the brain remained identical in mutant and wild-type (data not shown). This was not unexpected, because of the high expression level of ST8SiaII in nearly all brain regions at this developmental stage (Angata et al., 1997; Kurosawa et al., 1997; Hildebrandt et al., 1998; Ong et al., 1998). Strong differences were, however, observed in brains from older animals (5-6 weeks of age), in which Western blot analysis revealed a striking reduction in PSA expression in all brain regions analyzed (olfactory bulb, medulla oblongata, hippocampus, neocortex, and hypothalamus) (Fig. 2). In adult animals ( $>4$ months old), PSA expression dropped to relatively low, yet still detectable levels in whole brains of wild-type and heterozygous animals, but was undetectable in ST8SiaIV $^{-1-}$ mice (Fig. 3). After removal of PSA by endo-N, the intensity of NCAM protein bands was found to be identical in wild-type and mutant mice in all brain regions examined.

In the adult brain, two cell populations are known to express particularly high amounts of PSA and exhibit phenotypic abnor- malities in NCAM-deficient and endo-N-treated animals: neuroblasts migrating in the rostral migratory stream to the olfactory bulb (Rousselot et al., 1995) and granule and pyramidal neurons in the hippocampal formation (Seki and Arai, 1993). Accordingly, in wild-type mice, immunofluorescence studies indicated strong expression of PSA by neural precursors migrating in the subventricular zone of the lateral ventricle (Fig. 4a) and the rostral migratory stream (Fig. 4c). In ST8SiaIV-deficient mice, PSA expression of migratory cells was unaffected in the subventricular zone (Fig. 4b) and in the pathway (Fig. 4d). Furthermore, the typical chain-like organization of migrating precursors remained unchanged (Fig. $4 g, h)$, and there were no indications for an accumulation of neuroblasts in the rostral migratory stream (Fig. 4b,d,f), as has been reported for NCAM ${ }^{-1-}$ mice (Tomasiewicz et al., 1993; Chazal et al., 2000). Expression levels of the NCAM protein remained also unchanged in the ST8SiaIV mutants in these areas (Fig. 4e,f).

In the hippocampus of 6-week-old wild-type mice, strong expression of PSA was detected in the innermost layer of the dentate gyrus granule cells and in mossy fiber axons in the hilus region (Fig. $5 a$ ). At 6 months of age, PSA expression in this area was somewhat reduced, although still substantial (Fig. 5c). In wild-type animals of both ages, PSA immunoreactivity was also observed in the CA3 subfield (Fig. 5e), which represents the 

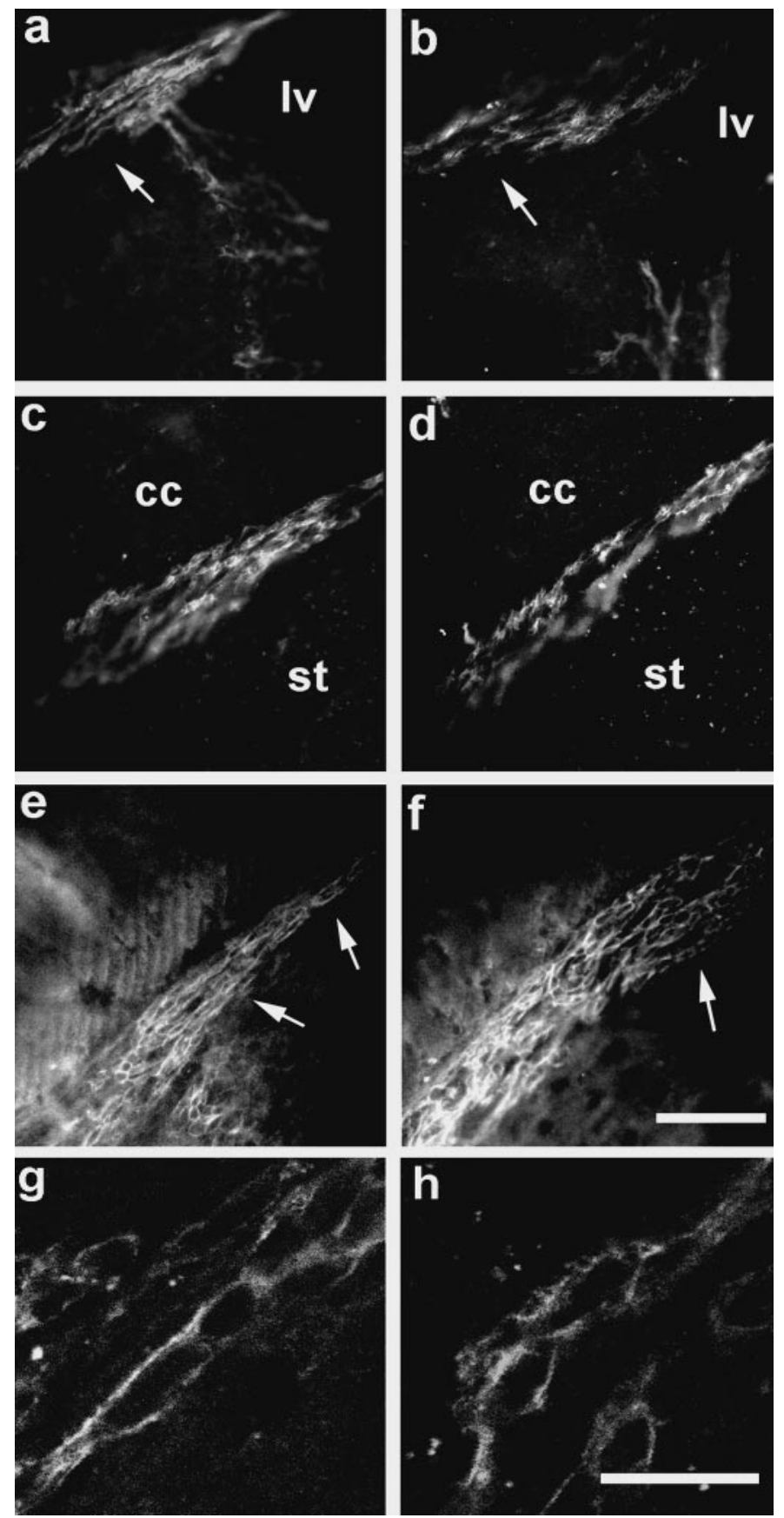

Figure 4. Expression of PSA in the rostral migratory stream is unaffected in ST8SiaIV mutant mice. Strong immunoreactivity for PSA is found in the forebrain region of 6-month-old wild-type $(a, c, g)$ as well as ST8SiaIVdeficient $(b, d, h)$ mice. The expression is confined to the migrating neuronal precursors in the subventricular zone of the lateral ventricle and at proximal $(a, b$, arrows $)$ as well as more distal parts $(c, d)$ of the rostral migratory stream. Expression of the NCAM protein is unaffected in the ST8SiaIV mutants $(e, f)$. Note that chain organization of the neural precursors and general morphology of the pathway are also unchanged $(e, f$, arrows). At a higher magnification $(g, h)$, the arrangement of PSAexpressing precursors in rostrocaudally oriented chains becomes even more obvious. $l v$, Lateral ventricle; $c c$, corpus callosum; st, striatum. Scale bars: $a-f, 75 \mu \mathrm{m} ; g, h, 15 \mu \mathrm{m}$.

mossy fiber termination field on the apical dendrites of pyramidal neurons.

In 6-week-old mutants, PSA expression in the dentate gyrus and hilus was reduced compared to the wild-type, but nevertheless still clearly detectable on the innermost layer of dentate gyrus granule neurons and individual mossy fibers (Fig. 5b, arrow). In contrast, at 6 months of age, PSA expression was virtually undetectable in the


Figure 5. Altered expression of PSA in the hippocampus of ST8SiaIVdeficient mice. Immunohistochemistry revealed the expression of high levels of PSA in the dentate gyrus and hilus regions of 6-week-old wild-type mice (a). In 6-month-old wild-type animals, PSA expression is somewhat fainter but still considerable $(c)$. In both situations the determinant appears to be confined to the innermost layer of dentate gyrus granule neurons and their axonal projections, the mossy fibers traveling in the hilus region. In 6-weekold ST8SiaIV-deficient animals $(b)$ PSA expression in the dentate gyrus $(d g)$ is already reduced. Nevertheless, many granule cells as well as individual mossy fibers (arrow) are still positive for PSA. In contrast, at 6 months of age, expression is almost undetectable in both $\mathrm{dg}$ and mossy fibers $(d)$. In addition, the entire CA3 area, representing the mossy fiber termination field on the pyramidal neurons, which in the wild-type still expresses large amounts of PSA at 6 month of age (e, arrow), appears entirely devoid of immunoreactivity in mutant animals $(f$, arrow $)$. Timm's staining for the presence of mossy fibers revealed that the laminated organization of the CA3 region typical for the wild-type $(g)$ is also maintained in the ST8SiaIVdeficient situation $(h)$. In the CA1 area of 17-d-old wild-type mice $(i)$ the expression of PSA in stratum pyramidale $(s p)$ appears stronger than in age-matched ST8SiaIV mutants $(j)$. However, in stratum radiatum $(s r)$, where Schaffer collaterals form synapses on CA1 pyramidal neurons, the appearance of punctate immunostaining is comparable in mutant and wildtype animals. In 6-month-old wild-type mice $(k)$ the intensity of immunostaining for PSA is weaker than in younger wild-type mice, but still much more prominent than in 6-month-old ST8SiaIV mutants $(l)$. The brains presented on panels $a-c$ or $i-l$ were morphologically processed in parallel and confocal images were acquired with the same settings. The amplification of immunofluorescent signal was higher in $i-l$ than in $a-c$. $C A 3$, Hippocampal $\mathrm{CA} 3$ region; $d g$, dentate gyrus; $h i$, hilus. Scale bar: $a-d, i-l, 75 \mu \mathrm{m} ; e, f, 150$ $\mu \mathrm{m} ; g, h, 200 \mu \mathrm{m}$. 
a

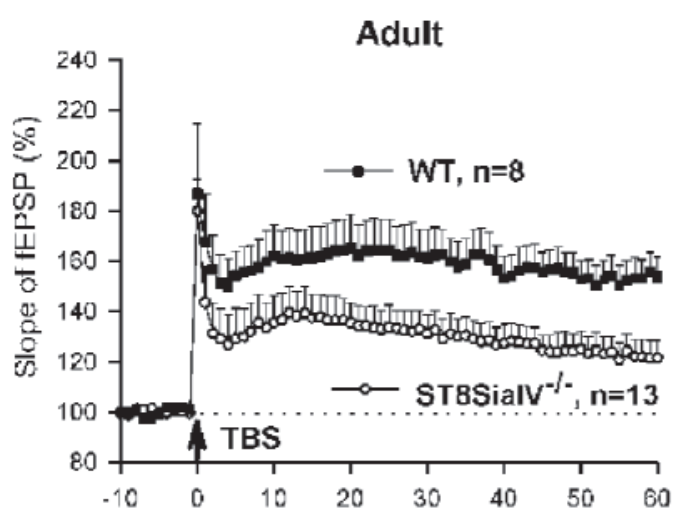

b



C

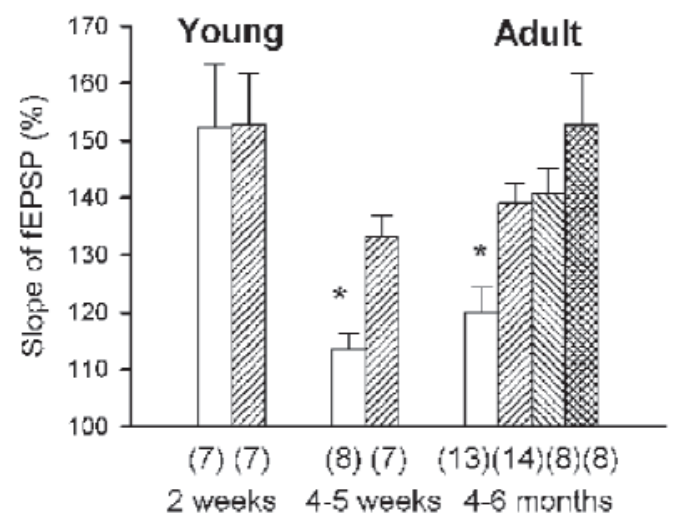

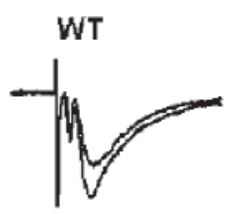

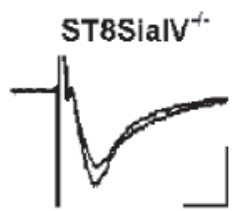

WT
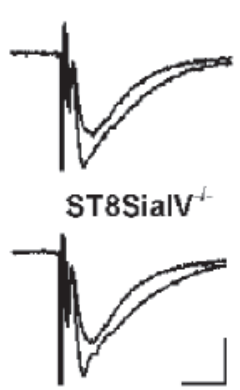

$\square$ ST8SiaIV $^{+-}$

WIIT WT, C57

\$IIIS WT, Ola

盉 WT, Ola/C57
Figure 6. LTP in the CA1 region is impaired in adult but normal in young ST8SiaIV ${ }^{-1-}$ mice. $a$, LTP in slices from 4- to 6-month-old mice. TBS (indicated by arrow) of Schaffer collaterals evoked a high increase in the slopes of fEPSPs recorded in the CA1 region of slices from wild-type $129 / \mathrm{Ola} \times \mathrm{C} 57 \mathrm{BL} / 6 \mathrm{~J}$ mice (WT, filled squares). In slices from ST8SiaIV ${ }^{-1-}$ mice, the potentiation immediately followed by TBS appeared normal, but then the slope declined to a level significantly lower than in wild-type mice (empty circles). Mean slope of fEPSPs recorded 0-10 min before TBS was taken as $100 \%$. Data represent mean + SEM, $n$ provides the number of tested slices from four wild-type and eight ST8SiaIV ${ }^{-1-}$ mice. Panels on the right show fEPSPs recorded before and $60 \mathrm{~min}$ after TBS. Calibration: $10 \mathrm{msec}, 500 \mu \mathrm{V} . b$, LTP in slices from 17- to 19 -d-old mice. Data represent mean + SEM from four wild-type and eight ST8SiaIV ${ }^{-1-}$ mice. PTP and LTP induced by TBS in mutant mice appeared normal. All abbreviations as in $a$. $c$, Developmental changes in LTP in the CA1 region of ST8SiaIV ${ }^{-1-}$ mice. In mutants, there is a reduction in LTP measured as the mean slope of fEPSPs recorded 50-60 min after TBS, between the second and fourth week of age. The level of LTP in wild-type mice remains the same after the second week of postnatal development and is independent of genetic background of the strains used. The numbers in parentheses indicate the number of tested slices. ${ }^{*} p<0.01$ significantly different from wild-type mice. dentate gyrus and hilus regions (Fig. $5 d$ ) as well as the entire CA3 subfield (Fig. 5f). We used Timm's staining to investigate the morphological consequences of the loss of PSA from the adult mossy fiber system. Unlike in NCAM-deficient mice, where the organization of the whole CA3 area is severely perturbed (Cremer et al., 1997), this labeling revealed a normal laminated organization of the structure with a clearly distinguishable stratum lucidum in the ST8SiaIV mutants (Fig 5, compare $g, h$ ), suggesting that the observed progressive reduction in PSA expression in ST8SiaIVdeficient mice does not grossly perturb the maintenance of the mossy fiber pathway.

PSA expression in the CA1 region was considerably lower than in CA3 and had a punctate appearance as shown before (Muller et al., 1996). Expression was highest in 17-d-old wild-type mice (Fig. 5i). In age-matched mutants (Fig. 5j) PSA immunoreactivity was strong, although slightly reduced compared to the controls. At 6 months there was still prominent PSA expression in the wild-type mice (Fig. $5 k$ ), whereas the CA1 region in mutants was negative at this level of detection (Fig. $5 l$ ).

\section{Impairment of LTP in CA1}

One consequence of NCAM deficiency is the impairment of LTP and LTD in the CA1 and LTP in the CA3 region of the hippocam- pus (Muller et al., 1996; Cremer et al., 1998). To determine the effects of a loss in PSA, we analyzed LTP and LTD in the hippocampus of 4- to 6-month-old ST8SiaIV ${ }^{-1-}$ mice with mixed C57BL/6J and 129/Ola genetic background (C57BL/6J $\times 129 / \mathrm{Ola})$ and age-matched groups of wild-type C57BL/6J, 129/Ola, and C57BL/6J $\times 129 /$ Ola mice. TBS reliably produced post-tetanic potentiation (PTP) and LTP in all slices from wild-type animals independently of their genetic background. The mean levels of LTP seen 50-60 min after TBS were $137.8 \pm 2.7 \%(n=14)$ for C57BL/6J mice, $140.6 \pm 4.6 \%(n=8)$ for 129/Ola mice, and $152.8 \pm 9.0 \%(n=8)$ for C57BL/6J $\times 129 /$ Ola mice (Fig. $6 a)$. Levels of PTP, measured as the maximal potentiation within the first 2 min after TBS for these three strains of mice, were $217.8 \pm$ $14.1,242 \pm 21.9$, and $189.8 \pm 27.3 \%$, respectively. There was no significant difference between strains in levels of LTP or PTP $(p>$ 0.1 ). Perfusion of slices $10 \mathrm{~min}$ before and during TBS with an antagonist to NMDA receptors $(50 \mu \mathrm{M}$ AP-5) resulted in a complete block of LTP $(103.2 \pm 0.8 \% ; n=3$; C57BL/6J mice). Field EPSPs evoked by stimulation of the control pathway were not significantly potentiated after TBS (mean slopes of fEPSP recorded 50-60 min after TBS in slices from three wild-type strains were in the range of $96.6-100.3 \% ; p>0.5)$, showing input specificity of the 
recorded LTP. Mutant mice exhibited normal levels of basic synaptic transmission measured as the amplitude of fEPSP at 50\% stimulation strength and paired-pulse facilitation with $50 \mathrm{msec}$ interstimulus interval (data not shown). PTP in mutants was also similar to that observed in wild-type mice $(191.2 \pm 16.7 \% ; n=13$; $p>0.1$ ), but mutants showed impaired LTP in comparison to wild-type mice in all genotypes $(123.9 \pm 4.6 \% ; n=13 ; p<0.05)$.

Because of the age-dependent decline of PSA expression (Fig. 5), we decided to compare levels of LTP in mutant and wild-type mice of different ages (Fig. $6 c$ ). In wild-type mice, there were no significant changes in the levels of LTP during development $(p>0.1)$. In 1-month-old mutant mice LTP was similar to that in 4- to 6-month-old mutants and significantly smaller than in 1-month-old wild-type mice $(113.5 \pm 2.9 \%, n=8$ vs $133.3 \pm 3.7 \%, n=7 ; p<$ 0.01). However, in 17- to 19-d-old mutant mice, high LTP was induced that was not significantly different from LTP in the agematched wild-type group (Fig. $6 b$ ). This level of LTP was higher than that in two groups of 4- to 5-week-old and 4- to 6-month-old mutant mice $(p<0.01$; Fig. $6 c)$. Thus, reduction in LTP develops in a rather narrow time window, between the second and fourth week of postnatal development when downregulation of PSA expression in the hippocampus occurs.

\section{LTD in CA1}

To produce LTD in hippocampal slices prepared from mice, two trains of 600 pulses were delivered with a $10 \mathrm{~min}$ interval. This stimulation induced a long-term reduction of the fEPSP slope by $>10 \%$ from the baseline in 10 of 11 slices prepared from $4-$ to 6-month-old C57BL/6J mice. On average, fEPSP slopes were reduced $50-60 \mathrm{~min}$ after induction of LTD to $77.4 \pm 3.5 \%(n=11$; Fig. $7 b$ ). Similar levels were recorded in 129/Ola and C57BL/ $6 \mathrm{~J} \times 129 /$ Ola mice (Fig. 7c). This LTD was NMDA receptordependent because the fEPSP slope remained unchanged (93.8 \pm $2.9 \% ; n=3$; C57BL $/ 6 \mathrm{~J}$ mice) when LTD was induced in the presence of the NMDA receptor antagonist AP-5. LTD was also input-specific, because fEPSPs evoked by stimulation of the control pathway were not affected: The levels of fEPSP slope in slices from $129 / \mathrm{Ola}$ and C57BL/6J $\times 129 /$ Ola mice were $99.3 \pm 4.3 \%(n=8)$ and $101.7 \pm 2.3 \%(n=7)$, respectively $(p>0.5)$. In adult mutant mice LTD was induced only in 1 of 6 slices, and the mean slope of fEPSPs was not decreased $(103.5 \pm 6.5 \% ; n=6$; Fig. $7 a)$.

LTD evoked in slices from 14- to 19 -d-old C57BL/6J mice (79 \pm $6.0 \% ; n=9$ ) was not significantly different from that observed in wild-type adult mice $(p>0.1$; Fig. $7 b, c)$. LTD evoked in slices from 13 - to 18 -d-old mutant mice $(87.1 \pm 3.7 \% ; n=8)$ was significantly higher than that in adult mutants $(p<0.05)$ and not different from LTD recorded in young wild-type mice $(p>0.2)$. Thus, there is age-specific impairment of both LTP and LTD in adult but not young mutant mice.

\section{Normal LTP in CA3}

Field EPSPs evoked in CA3 pyramidal cells by mossy fiber stimulation are known to be fast and to exhibit paired-pulse facilitation and potentiation during $0.33 \mathrm{~Hz}$ stimulation. These criteria were taken to search for responses that were further pharmacologically identified using L-CCG1 as an agonist of type II metabotropic glutamate receptors, which is known to downregulate synaptic transmission in CA3 mossy fiber synapses (Cremer et al., 1998; Maccaferri et al., 1998; Yeckel et al., 1999). Low-frequency stimulation $(0.33 \mathrm{~Hz})$ potentiated fEPSPs to $\sim 250 \%$ in C57BL $/ 6 \mathrm{~J}$ and ST8SiaIV $^{-1-}$ mice (Fig. $8 a$ ). L-CCG1 diminished the amplitude of fEPSPs in C57BL/6J and ST8SiaIV ${ }^{-1-}$ mice by $80 \%$ (Fig. $8 b$ ). The NMDA receptor antagonist AP-5 did not affect the amplitude of selected fEPSPs in either C57BL/6J or in ST8SiaIV ${ }^{-1-}$ mice (Fig. $8 c$ ). HFS performed in the presence of AP-5 induced a strong increase in fEPSP amplitude (Fig. $8 c$ ). Maximal potentiation during the first 2 min after HFS was $\sim 700 \%$, and mean potentiation measured $50-60$ min after induction of LTP was $\sim 180 \%$, resembling reported profiles of LTP in CA3 (Maccaferri et al., 1998; Yeckel et al., 1999). There was no difference between



Figure 7. LTD in the CA1 region is impaired in adult but normal in young ST8SiaIV ${ }^{-1-}$ mice. $A$, LTD in slices from 4- to 6-month-old mice. Two trains of low-frequency stimulation $(1 \mathrm{~Hz}$, indicated by horizontal bars) of Schaffer collaterals reliably decreased the slopes of fEPSPs in slices from wild-type mice ( $W T$, filled squares). In slices from ST8SiaIV ${ }^{-/-}$mice, the slope returned to the baseline (empty circles). Mean slope of fEPSPs recorded $10 \mathrm{~min}$ before the first train was taken as $100 \%$. Data represent mean \pm SEM, $n$ provides the number of tested slices from six wild-type and four ST8SiaIV ${ }^{-}$mice. The panels on the right show fEPSPs in wild-type and ST8SiaIV ${ }^{-1-}$ mice before and $60 \mathrm{~min}$ after induction of LTD. Calibration: $10 \mathrm{msec}, 250 \mu \mathrm{V} . b$, LTD in slices from 13- to 19-d-old mice. Data represent mean + SEM from six wild-type and five ST8SiaIV ${ }^{-1-}$ mice. LTD in mutant mice appeared normal. All abbreviations as in $a$. $c$, Developmental changes in LTD in the CA1 region of ST8SiaIV ${ }^{-/-}$mice. In mutants, there is an age-dependent impairment of LTD, measured as the mean slope of fEPSPs recorded 50-60 min after induction of LTD. The levels of LTD are similar in wild-type mice of different genetic backgrounds and ages. The numbers in parentheses indicate the number of tested slices. $* p<0.01$ significantly different from wild-type mice.

C57BL/6J and ST8SiaIV ${ }^{-/-}$mice in short- or long-term potentiation $(p>0.5)$.

To examine the possibility that mossy fibers in mutants still express low amounts of PSA that could be sufficient to maintain LTP, we recorded mossy fiber LTP in slices from mutant mice incubated with endo-N. The effectiveness of endo-N treatment was verified by the loss of PSA immunoreactivity. Treatment of slices with endo-N did not reduce mossy fiber PTP or LTP $(p>$ 0.2 ; Fig. $8 d$ ).

To exclude the possibility that the impairment in LTP in CA1 but 

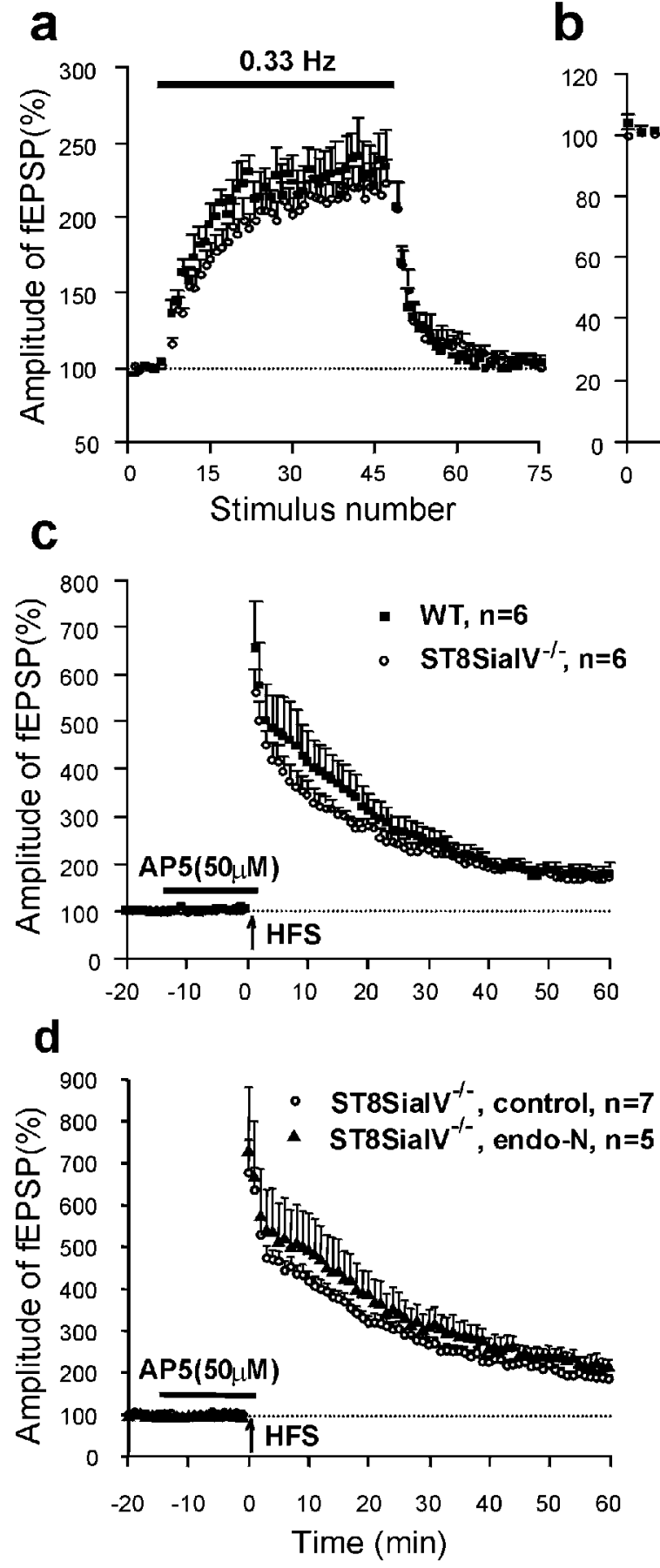
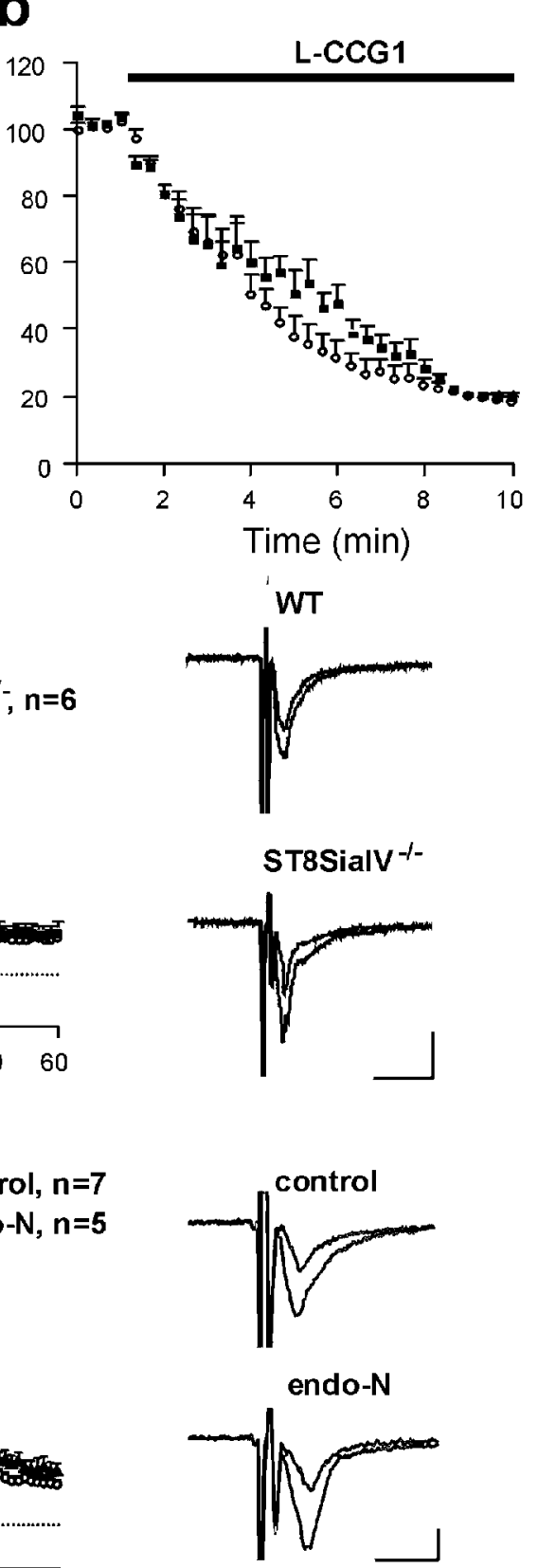

Figure 8. Normal LTP in the CA3 region of ST8SiaIV ${ }^{-1-}$ mice. $a$, Stimulation of mossy fibers with a frequency of $0.33 \mathrm{~Hz}$ increased the amplitudes of fEPSPs in acute slices from both wild-type $\mathrm{C} 57 \mathrm{BL} / 6 \mathrm{~J}$ and ST8SiaIV ${ }^{-1-}$ mice (filled squares and empty circles, respectively). Data in $a$--c are from five wild-type and three ST8SiaIV ${ }^{-/-}$mice. Here and below, the graphs represent normalized mean + SEM, $n$ provides the number of tested slices. $b$, Application of the type II metabotropic glutamate receptor agonist L-CCGI $(10 \mu \mathrm{M})$ reduced the amplitude of fEPSPs in slices from both wild-type and ST8SiaIV ${ }^{-/-}$mice. $c$, Highfrequency stimulation ( $H F S$, indicated by arrow) of mossy fibers evoked a similar increase in slopes of fEPSPs in slices from wild-type and ST8SiaIV ${ }^{-1-}$ mice. Mean slope of fEPSPs recorded 0-10 min before HFS was taken as $100 \%$. Insets show averaged fEPSPs recorded before and $60 \mathrm{~min}$ after induction of LTP in wild-type and ST8SiaIV ${ }^{-1-}$ mice. Calibration: $10 \mathrm{msec}, 100 \mu \mathrm{V} . d$, HFS of mossy fibers evoked similar LTP in slices with and without endo-N treatment. Recordings were performed in slices from five ST8SiaIV ${ }^{-/-}$mice. not in CA3 was attributable to differences in slice preparation, we recorded LTP from CA1 and CA3 in slices prepared identically from the same 6-month-old mutant mouse according to the "CA3 protocol". Under these conditions, LTP could not be induced in CA1 (mean slopes of fEPSPs collected in two slices 50-60 min after TBS were 91.1 and $103.0 \%$ of the baseline), but was normal in CA3 (176.9\%). Normal LTP was induced in CA1 in slices from wild-type mice prepared according to the "CA3 protocol" (151.6 $14.6 \% ; n=4)$.

\section{DISCUSSION}

Mice homozygous for a null mutation in the polysialyltransferase ST8SiaIV gene revealed normal development of gross anatomical features. Because of the high expression level of the other identified and developmentally early active polysialyltransferase ST8SiaII, there was no obvious reduction in the amount of polysialylated NCAM in 4-d-old brain and all other organs examined. However, during postnatal development, a progressive loss of PSA was observed in all brain regions examined, especially in the CA1 and CA3-CA4 regions, with exception of the rostral migratory stream. The strong reduction of PSA in the hilus region of the hippocampus (CA4) and CA3 is in agreement with data from Hildebrandt et al. (1998), showing that at $21 \mathrm{~d}$ ST8SiaII is only expressed in the inner layer of the dentate granule cells in rat hippocampus, whereas ST8SiaIV remains expressed throughout the hippocampus.

Migration of neuronal precursors in the rostral migratory stream (Tomasiewicz et al., 1993) and axonal growth of mossy fibers in the hippocampus (Cremer et al., 1997, 1999; Seki and Rutishauser, 1998) are affected in adult NCAM-deficient mice. 
Table 1. Roles of NCAM lacking PSA, PSA, and polysialyltransferases in neural development and synaptic plasticity

\begin{tabular}{|c|c|c|c|c|}
\hline Function & $\mathrm{NCAM}^{-/-}$Mutant & Endo-N treatment & ST8SiaIV $^{-/-}$Mutant & Putative molecular basis \\
\hline Migration of neural precursors & - & - & + & PSA (ST8SiaII) \\
\hline Lamination of mossy fibers & - & - & + & PSA (ST8SiaII) \\
\hline LTP and LTD in CA1 & - & - & $-{ }^{a}$ & PSA (ST8SiaIV) \\
\hline LTP in CA3 & - & $+^{b}$ & + & NCAM glycoprotein without PSA \\
\hline
\end{tabular}

- Impairment of function; +, normal function.

${ }^{a}$ Only in adult mice.

${ }^{b}$ In ST8SiaIV ${ }^{-/-}$mice.

Experiments using the PSA-degrading enzyme endo-N provided strong evidence that loss of PSA rather than loss of NCAM is responsible for these changes (Ono et al., 1994). In the ST8SiaIV $^{-/-}$mice investigated here, PSA expression is strongly reduced in most brain regions compared to wild-type animals during postnatal stages. Nevertheless, in the rostral migratory stream, polysialylation of NCAM is unaffected even in the 6-month-old mice, suggesting that in this system polysialylation activity is maintained by the remaining transferase ST8SiaII (Table 1). Accordingly, chain migration of the PSA-expressing neuronal precursors is normal, and we found no accumulation of precursors in the pathway or differences in the size of the olfactory bulb, as has been described for NCAM-deficient mice.

The situation appears different in the hippocampal formation, where PSA is expressed in the dentate gyrus as well as in the CA4, CA3, and CA1 subfields. Here, PSA expression in ST8SiaIV mutants is high in the young animals, but drops dramatically during later postnatal stages. Thus, ST8SiaII, possibly in concert with ST8SiaIV, is responsible for polysialylation during the development of the system, but only the latter one generates PSA in the adult animal. However, morphologically the entire structure appears normal, suggesting that the striking lamination defect in NCAM-deficient mice (Cremer et al., 1997; Seki and Rutishauser, 1998 ) is attributable to the lack of PSA during development of the system and that this phenotype reflects more the absence of PSA generated by ST8SiaII (Table 1). In this case, mice lacking both ST8SiaIV and ST8SiaII, which will soon be available, are expected to exhibit the same deficiencies as NCAM-deficient or endo-N treated mice. However, the loss of PSA from the hippocampus without changes in the organization of the structure, allowed us to address the involvement of this carbohydrate in synaptic plasticity independent of the NCAM glycoprotein.

NCAM deficiency results in impaired LTP in CA1 of the hippocampus in organotypic slice cultures and in acute slices (Muller et al., 1996; A. Artola, unpublished observations; but see Holst et al., 1998; Dityatev et al., 1999). Furthermore, examination of endo$\mathrm{N}$-treated hippocampal slice cultures or acute slice preparations yielded similar results (Becker et al., 1996; Muller et al., 1996). Endo-N treatment was also found to cause a block of LTD in CA1 (Muller et al., 1996). We here show that absence of ST8SiaIV, which results in reduced PSA expression in CA1 in adult mice, also impairs LTP and LTD at Schaffer collateral-CA1 synapses, thus providing genetic evidence for the essential role of PSA produced by ST8SiaIV in synaptic plasticity at these sites (Table 1). Basal synaptic activity and PTP, by contrast, were normal in the mutant, suggesting that the basic synaptic machinery was not affected by the mutation. Normal PTP in Schaffer collateral synapses in the presence of endo-N was also found after high-frequency stimulation of acute hippocampal slices (Becker et al., 1996), but not when potentiation was induced in organotypic cultures (Muller et al., 1996).

Synaptic plasticity in CA3 was normal in ST8SiaIV ${ }^{-1-}$ mice. This observation is different from the results showing impaired CA3 LTP in NCAM ${ }^{-1-}$ mice in which PSA is virtually absent in this region (Cremer et al., 1998). There are two explanations for impaired long-term plasticity in CA3 of NCAM but not of ST8SiaIV knock-out mice. One is that the NCAM glycoprotein but not its PSA moiety may play an essential role in synaptic plasticity.
It is noteworthy in this context that mossy fiber synapses do not express detectable levels of PSA in adult rat and mice (Seki and Rutishauser, 1998; Seki and Arai, 1999). Whereas PSA is detectable in spine synapses in the CA3/CA4 and CA1 regions of the hippocampus, but not detectable in giant mossy fiber terminals, NCAM protein is detectable in both types of structures (T. Schuster, M. Krug, and M. Schachner, unpublished observations). Alternatively, impaired CA3 LTP could be an indirect consequence of the altered distribution of mossy fiber terminals in $\mathrm{NCAM}^{-1-}$ mice, which is not observed when ST8SiaIV is absent. A developmental defect is unlikely to account for the deficit in CA1 LTP and LTD in ST8SiaIV $^{-1-}$ mice, because ST8SiaII appears to compensate for ST8SiaIV deficiency at earlier stages and we observed reduced LTP, LTD, and PSA levels only in the adult hippocampus.

Our findings of impaired NMDA receptor-dependent synaptic plasticity in CA1 and normal NMDA receptor-independent synaptic plasticity in CA3 suggest that PSA in synaptic membranes is an important determinant of some but not all forms of synaptic plasticity in the hippocampus. It will be interesting to determine which other types of synapses in the brain are affected by PSA expression. Although in wild-type mice, PSA has been suggested to be present in the CA1 region on neurons and glia from light microscopic studies (Fox et al., 1995; Muller et al., 1996), it remains to be determined whether PSA is involved in presynaptic or postsynaptic processes by immunoelectron microscopic studies. Our electrophysiological experiments support the view that PSA expression on preterminal axons is not necessary for expression of normal LTP at the mossy fiber synapses.

The exact mechanisms underlying an increase in synaptic efficacy during LTP (expression of LTP) are not fully understood, but it appears that they involve changes in the number and functional properties of AMPA-type of glutamate receptors (Barria et al., 1997; Benke et al., 1998; Shi et al., 1999). In view of these results, it is noteworthy that colominic acid, a homopolymer of sialic acid, can prolong AMPA receptor channel open time and increase its bursting activity (Suppiramaniam et al., 1999). Enzymatic removal of sialic acid from hippocampal membrane fractions modified binding of AMPA to AMPA receptors (Hoffman et al., 1997). Furthermore, there is an activity-dependent rapid shift of PSA-NCAM to the cell surface in cultured neurons, endocrine cells, and in hippocampal slice cultures (Kiss et al., 1994; Muller et al., 1996). Muller et al. (1996) proposed that neural activity leads to increased exocytosis of PSA-NCAM at the hippocampal synapses creating an "anti-adhesive" environment as a prerequisite for structural changes. Block of perforated synapse formation by endo-N treatment supports an involvement of PSA in structural changes at the synapse (Toni et al., 1998). If PSA is differentially distributed in different locations of the synaptic membranes, this could also change diff usion of soluble factors including neurotrophins (Muller et al., 2000) and neurotransmitters into and out of the synaptic cleft by altering its microenvironment. Demonstration of a direct modulation of reconstituted AMPA receptors by PSA strongly suggests that in addition to promoting structural changes at the synapse, an activity-dependent increase of PSA-NCAM on postsynaptic sites could directly enhance AMPA receptor activity and therefore increase synaptic strength. 


\section{REFERENCES}

Anderson WW, Collingridge GL (1997) Data acquisition program for on-line analysis of long-term potentiation and long-term depression. Soc Neurosci Abstr 23:665.

Angata K, Nakayama J, Fredette B, Chong K, Ranscht B, Fukuda M (1997) Human STX polysialyltransferase forms the embryonic form of the neural cell adhesion molecule. Tissue-specific expression, neurite outgrowth, and chromosomal localization in comparison with another polysialyltransferase, PST. J Biol Chem 272:7182-7190.

Barria A, Muller D, Derkach V, Griffith LC, Soderling TR (1997) Regulatory phosphorylation of AMPA-type glutamate receptors by CaM-KII during long-term potentiation. Science 276:2042-2045.

Becker CG, Artola A, Gerardy-Schahn R, Becker T, Welzl H, Schachner M (1996) The polysialic acid modification of the neural cell adhesion molecule is involved in spatial learning and hippocampal long-term potentiation. J Neurosci Res 45:143-152.

Benke TA, Luthi A, Isaac JT, Collingridge GL (1998) Modulation of AMPA receptor unitary conductance by synaptic activity. Nature 393:793-797.

Chazal G, Durbec P, Jankovski A, Rougon G, Cremer H (2000) Consequences of neural cell adhesion molecule deficiency on the migration of neuronal precursors in the rostral migratory stream of the adult mouse. J Neurosci 20:1446-1457.

Claiborne BJ, Xiang Z, Brown TH (1993) Hippocampal circuitry complicates analysis of long-term potentiation in mossy fiber synapses. Hippocampus 3:115-121.

Cremer H, Lange R, Christoph A, Plomann M, Vopper G, Roes J, Brown R, Baldwin S, Kraemer P, Scheff S, Barthels D, Rajewsky K, Wille W (1994) Inactivation of the N-CAM gene in mice results in size reduction of the olfactory bulb and deficits in spatial learning. Nature 367:455-459.

Cremer H, Chazal G, Goridis C, Represa A (1997) NCAM is essential for axonal growth and fasciculation in the hippocampus. Mol Cell Neurosci 8:323-335.

Cremer H, Chazal G, Carleton A, Goridis C, Vincent JD, Lledo PM (1998) Long-term but not short-term plasticity at mossy fiber synapses is impaired in neural cell adhesion molecule-deficient mice. Proc Natl Acad Sci USA 95:13242-13247.

Dityatev A, Stork O, Tsai J, Schachner M (1999) A role of neural cell adhesion molecule (NCAM) in synaptogenesis and synaptic function. Cell Biol Intern 23:129.

Eckhardt M, Gerardy-Schahn R (1998) Genomic organization of the murine polysialyltransferase gene ST8SiaIV (PST-1). Glycobiology 8:1165-1172.

Eckhardt M, Mühlenhoff M, Bethe A, Koopman J, Frosch M, GerardySchahn R (1995) Molecular characterization of eukaryotic polysialyltransferase-1. Nature 373:715-718.

Edwards FA, Konnerth A, Sakmann B (1990) Quantal analysis of inhibitory synaptic transmission in the dentate gyrus of rat hippocampal slices: a patch-clamp study. J Physiol (Lond) 430:213-249.

Fox GB, Kennedy N, Regan CM (1995) Polysialylated neural cell adhesion molecule expression by neurons and astroglial processes in the rat dentate gyrus declines dramatically with increasing age. Int J Dev Neurosci 13:663-672.

Frosch M, Gorgen I, Boulnois GJ, Timmis KN, Bitter-Suermann D (1985) NZB mouse system for production of monoclonal antibodies to weak bacterial antigens: isolation of an $\mathrm{IgG}$ antibody to the polysaccharide capsules of Escherichia coli K1 and group B meningococci. Proc Nat Acad Sci USA 82:1194-1198.

Gennarini G, Hirsch MR, He HT, Hirn M, Finne J, Goridis C (1986) Differential expression of mouse neural cell adhesion molecule (N-CAM) mRNA species during brain development and in neural cell lines. J Neurosci 6:1983-1990.

Gerardy-Schahn R, Eckhardt M (1994) Hot spots of antigenicity in the neural cell adhesion molecule NCAM. Int J Cancer Suppl 8:38-42.

Glass JD, Lee W, Shen H, Watanabe M (1994) Expression of immunoreactive polysialylated neural cell adhesion molecule in the suprachiasmatic nucleus. Neuroendocrinology 60:87-95.

Goodman CS, Davis GW, Zito K (1997) The many faces of fasciclin. II: Genetic analysis reveals multiple roles for a cell adhesion molecule during the generation of neuronal specificity. Cold Spring Harb Symp Quant Biol 62:479-491.

Hildebrandt H, Becker C, Mürau M, Gerardy-Schahn R, Rahmann H (1998) Heterogeneous expression of the polysialyltransferases ST8Sia II and ST8Sia IV during postnatal rat brain development. J Neurochem $71: 2339-2348$.

Hoffman KB, Kessler M, Lynch G (1997) Sialic acid residues indirectly modulate the binding properties of AMPA-type glutamate receptors. Brain Res 753:309-314.

Holst BD, Vanderklish PW, Krushel LA, Zhou W, Langdon RB, McWhirter JR, Edelman GM, Crossin KL (1998) Allosteric modulation of AMPA-type glutamate receptors increases activity of the promoter for the neural cell adhesion molecule, N-CAM Proc Natl Acad Sci USA 95:2597-2602.

Kerr DS, Abraham WC (1995) Cooperative interactions among afferents govern the induction of homosynaptic long-term depression in the hippocampus. Proc Natl Acad Sci USA 92:11637-11641.
Kiss JZ, Rougon G (1997) Cell biology of polysialic acid. Curr Opin Neurobiol 7:640-646.

Kiss JZ, Wang C, Olive S, Rougon G, Lang J, Baetens D, Harry D, Pralong WF (1994) Activity-dependent mobilization of the adhesion molecule polysialic NCAM to the cell surface of neurons and endocrine cells. EMBO J 13:5284-5292.

Kojima N, Kono M, Yoshida Y, Tachida Y, Nakafuku M, Tsuji S (1996) Biosynthesis and expression of polysialic acid on the neural cell adhesion molecule is predominantly directed by ST8Sia II/STX during in vitro neuronal differentiation. J Biol Chem 271:22058-22062.

Kurosawa N, Yoshida Y, Kojima N, Tsuji S (1997) Polysialic acid synthase (ST8SiaII/STX). mRNA expression in the developing mouse central nervous system. J Neurochem 69:494-503.

Lackie P, Zuber C, Roth J (1993) Expression patterns of polysialic acid during vertebrate organogenesis. In: Polysialic acid (Roth J, Rutishauser U, Troy FA, eds), pp 263-278. Basel, Switzerland: Birkhäuser Verlag.

Livingston BD, Paulson JC (1993) Polymerase chain reaction cloning of a developmentally regulated member of the sialyltransferase gene family. J Biol Chem 268:11504-11507.

Lois C, Garcia-Verdugo JM, Alvarez-Buylla A (1996) Chain migration of neuronal precursors. Science 271:978-981.

Maccaferri G, Toth K, McBain CJ (1998) Target-specific expression of presynaptic mossy fiber plasticity. Science 279:1368-1370.

Mansour SL, Thomas KR, Capecchi MR (1988) Disruption of the protooncogene int- 2 in mouse embryo-derived stem cells: a general strategy for targeting mutations to non-selectable genes. Nature 336:348-352.

Mayford M, Barzilai A, Keller F, Schacher S, Kandel ER (1992) Modulation of an NCAM-related adhesion molecule with long-term synaptic plasticity in Aplysia. Science 256:638-644.

Mühlenhoff M, Eckhardt M, Bethe A, Frosch M, Gerardy-Schahn R (1996a) Polysialylation of NCAM by a single enzyme. Curr Biol 6:1188-1191.

Mühlenhoff M, Eckhardt M, Bethe A, Frosch M, Gerardy-Schahn R (1996b) Autocatalytic polysialylation of polysialyltransferase-1. EMBO J 15:6943-6950.

Mühlenhoff M, Eckhardt M, Gerardy-Schahn R (1998) Polysialic acid: three-dimensional structure, biosynthesis and function. Curr Opin Struct Biol 8:558-564.

Muller D, Wang C, Skibo G, Toni G, Cremer H, Calaora V, Rougon G, Kiss JZ (1996) PSA-NCAM is required for activity-induced synaptic plasticity. Neuron 17:413-422.

Muller D, Djebbara-Hannas Z, Jourdain P, Vutskitz L, Durbec P, Rougon G, Kiss JZ (2000) Brain-derived neurotrophic factor restores long-term potentiation in polysialic acid-neural cell adhesion molecule-deficient hippocampus. Proc Natl Acad Sci USA, in press.

Nakayama J, Fukuda M (1996) A human polysialyltransferase directs in vitro synthesis of polysialic acid. J Biol Chem 271:1829-1832.

Nakayama J, Fukuda MN, Fredette B, Ranscht B, Fukuda M (1995) Expression cloning of a human polysialyltransferase that forms the polysialylated neural cell adhesion molecule present in embryonic brain. Proc Natl Acad Sci USA 92:7031-7035.

Ong E, Nakayama J, Angata K, Reyes L, Katsuyama T, Arai Y, Fukuda M (1998) Developmental regulation of polysialic acid synthesis in mouse directed by two polysialyltransferases, PST and STX. Glycobiology $8: 415-424$.

Ono K, Tomasiewicz H, Magnuson T, Rutishauser U (1994) N-CAM mutation inhibits tangential neuronal migration and is phenocopied by enzymatic removal of polysialic acid. Neuron 13:595-609.

Phillips GR, Krushel LA, Crossin KL (1997) Developmental expression of two rat sialyltransferases that modify the neural cell adhesion molecule, N-CAM. Dev Brain Res 102:143-155.

Rousselot P, Lois C, Alvarez-Buylla A (1995) Embryonic (PSA) N-CAM reveals chains of migrating neuroblasts between the lateral ventricle and the olfactory bulb of adult mice. J Comp Neurol 351:51-61.

Rutishauser U (1996) Polysialic acid and the regulation of cell interactions. Curr Opin Cell Biol 8:679-684.

Rutishauser U, Landmesser L (1996) Polysialic acid in the vertebrate nervous system: a promoter of plasticity in cell-cell interactions. Trends Neurosci 19:422-427.

Sambrook J, Fritsch EF, Maniatis T (1989) Molecular cloning: a laboratory manual. Cold Spring Harbor: Cold Spring Harbor Laboratory:

Schachner M (1997) Neural recognition molecules and synaptic plasticity. Curr Opin Cell Biol 9:627-634.

Seki T, Arai Y (1993) Distribution and possible roles of the highly polysialylated neural cell adhesion molecule (NCAM-H) in the developing and adult central nervous system. Neurosci Res 17:265-290.

Seki T, Arai Y (1999) Different polysialic acid-neural cell adhesion molecule expression patterns in distinct types of mossy fiber boutons in the adult hippocampus. J Comp Neurol 410:115-125.

Seki T, Rutishauser U (1998) Removal of polysialic acid-neural cell adhesion molecule induces aberrant mossy fiber innervation and ectopic synaptogenesis in the hippocampus. J Neurosci 18:3757-3766.

Shi SH, Hayashi Y, Petralia RS, Zaman SH, Wenthold RJ, Svoboda K, Malinow R (1999) Rapid spine delivery and redistribution of AMPA receptors after synaptic NMDA receptor activation. Science 284:1811-1816. 
Suppiramaniam V, Yilma S, Bowens A, Manivannan K, Bahr B, Dityatev A (1999) Colominic acid (polysialic acid) alters the channel properties of AMPA receptors reconstituted in lipid bilayers. Soc Neurosci Abstr 25:594.10.

Theodosis DT, Rougon G, Poulain DA (1991) Retention of embryonic features by an adult neuronal system capable of plasticity: polysialylated neural cell adhesion molecule in the hypothalamo-neurohypophysial system. Proc Natl Acad Sci USA 88:5494-5498.

Tomasiewicz H, Ono K, Yee D, Thompson C, Goridis C, Rutishauser U, Magnuson T (1993) Genetic deletion of a neural cell adhesion molecule variant (N-CAM-180) produces distinct defects in the central nervous system. Neuron 11:1163-1174.

Toni N, Buchs PA, Bron C, Sadlo P, Smithies D, Muller D (1998) Long- term potentiation in the CA1 hippocampal formation may induce synaptogenesis by splitting of activated dendritic spines. Abstr Swiss Soc Neurosci 3:50.

Wood GK, Liang JJ, Flores G, Ahmad S, Quirion R, Srivastava LK (1997) Cloning and in situ hybridization analysis of the expression of polysialyltransferase mRNA in the developing and adult rat brain. Mol Brain Res 51:69-81.

Yeckel MF, Kapur A, Johnston D (1999) Multiple forms of LTP in hippocampal CA3 neurons use a common postsynaptic mechanism. Nat Neurosci 2:625-633.

Yoshida Y, Kojima N, Tsuji S (1995) Molecular cloning and characterization of a third type of N-glycan $\alpha 2$, 8-sialyltransferase from mouse lung. J Biochem 118:658-664. 